\title{
7 Contornos da prosa modernista em The Waves
}

\author{
Patricia Marouvo Fagundes \\ Universidade Federal do Acre, Brasil \\ https://orcid.org/0000-0001-5506-953x
}

\section{RESUMO}

Este artigo busca investigar a maneira como a forma do romance The Waves (1931), de Virginia Woolf, se instaura como expressão de sua prosa modernista, política e feminista. As diferentes vozes das seis personagens principais são atravessadas pelo tempo, da infância à velhice, e entre elas são inseridos interlúdios que, reunidos, apresentam o decorrer de um dia, instâncias paralelas que se interpenetram na complementaridade entre ser humano e natureza de que faz parte. A enorme importância que a autora sempre deu para a forma de seus textos é inegável, em especial ao explorá-la ao máximo, a ponto de esgarçar as fronteiras entre os gêneros literários e não-literários. Por meio de um apanhado de seus ensaios e passagens de seus diários, além da contribuição de textos seminais da crítica woolfiana, propõe-se que uma forma significante se avulta à maneira de recorte e colagem de cores e brilhos, luzes e sombras que encerrem a multiplicidade una que 0 todo de um mosaico compõe.

PALAVRAS-CHAVE: Prosa modernista; Virginia Woolf; The Waves.

\section{Outlines of the Modernist Prose in The Waves}

\section{ABSTRACT}

This article aims to investigate how the form of Virginia Woolf's novel The Waves (1931) presents itself as the expression of her political and feminist modernist prose. The voices of the six different main characters unfold throughout time, from childhood to old age, and they are interspersed with interludes that present the course of a day, parallel instances that intertwine in the complementarity of human being and nature. The immense importance the author always placed on the form of her texts is not under question, especially as she explored it to the point of blurring the boundaries of both literary and non-literary genres. Based on several of her essays and excerpts from her diaries, besides taking into consideration the contribution of seminal texts within Woolf scholarship, this article proposes that a significant form can be envisioned as a collage of colors, lights and shadows that enclose the multiplicity of oneness of which this mosaic consists.

KEYWORDS: Modernist Prose; Virginia Woolf; The Waves. 
O romance The Waves, ou As ondas (1931), de Virginia Woolf, sonoriza o quebrar das ondas em consonância plena com o pulsar do espírito humano em sua travessia de vida pensada-sentida. Nos entre-caminhos que se delineiam à medida que a coragem permite o agir se fazer sentir, os ciclos da vida humana se mesclam e confundem com o ciclo da vida maior que a engloba, necessariamente desembocando na morte de cada dia, rumo ao destino final frente à morte derradeira. A atração irresistível entre o chamado de seis diferentes destinos que se entrelaçam uns com os outros encorpa o texto literário, que se constrói em uma forma harmoniosa e só aparentemente desestruturada e fragmentada. A trama tem uma organicidade própria, revelando uma referência clara e direta das partes com o todo, das personagens umas com as outras, das diferentes fases da vida com as etapas de um dia, da vida humana com o ser.

O enredo reúne cenas de um dia de verão, do nascer ao pôr do sol em uma praia inglesa, alternadamente conectadas a cenas das vidas de seis personagens principais, Bernard, Neville, Louis, Susan, Jinny e Rhoda, suas infâncias até suas velhices. A infância das personagens, lúdica e fragmentada como em um sonho rememorado, se passa em Elvedon, em um delírio que parece ecoar os primeiros anos de Virginia Woolf na casa de veraneio da família Stephen. Seu olhar ficaria para sempre delimitado por instantes cujo impacto lhe causaram a impressão que seria revisitada em diversas obras no decorrer de sua carreira, como declara em "A Sketch of the Past" (1939-1940):
Se a vida tem alguma base sobre a qual se fundamenta, se ela é um recipiente que alguém enche e enche - então, meu recipiente, sem dúvida alguma, se fundamenta nesta memória. Deitada, e par- cialmente adormecida, na cama no quarto das crianças em St. Ives. Ouvindo as ondas quebrarem um, dois, um, dois e espirrando um jato d'água sobre a praia; e depois quebrando um, dois, um, dois, por trás do amarelo das persianas. Ouvindo a persiana arrastar sua corrente pelo chão enquan- to o vento soprava. Deitando e ouvindo esse esguicho e vendo essa luz, e sentindo ser praticamente impossível que eu estivesse ali; sentindo o êxtase mais puro que posso conceber ${ }^{1}$ (WOOLF, 1985, p. 64-65).

A memória de um momento longínquo da infância em St. Ives dá o tom de luz e energia emanadas de cores e ritmos do local à beira-mar onde o quarto das crianças se encontra. A luz de um amarelo pálido descerra o dia claro e ensolarado por trás das persianas. A energia ritmada pelas ondas, previsíveis a ponto de se tornarem sonolentas, irradia a sensação de vigília levemente adormecida, embaçando esta lembrança e relegando-a aos mistérios de uma dimensão entre o sonho e a realidade. Incrível pensar que um momento aparentemente tão distante e desconexo possa integrar as primeiras páginas das memórias da autora e ser descrito com precisão e firmeza ao ser declarado o momento que serviria de fundamento para a apreensão do todo que até

\footnotetext{
${ }^{1}$ If life has a base that it stands upon, if it is a bowl that one fills and fills - then my bowl without a doubt stands upon this memory. It is of lying half asleep, half awake, in bed in the nursery at St Ives. It is of hearing the waves breaking one, two, one, two, and sending a splash of water over the beach; and then breaking, one, two, one, two, behind a yellow blind. It is of hearing the blind draw its little acorn across the floor as the wind blew the blind out. It is of lying and hearing this splash and seeing this light, and feeling, it is almost impossible that I should be here; of feeling the pure ecstasy I can conceive. Todas as traduções são de minha autoria.
} 
então havia sido uma vida. Apenas dissimuladamente remota, esta passagem revela a proximidade da intimidade marcada pela origem.

Se Virginia Woolf afirma ser essa uma de suas primeiras memórias, ainda muito jovem, devemos necessariamente entender sua relevância e procurar desenvolver a extensão de possíveis consequências no seu trabalho. É precisamente por causa de um leve amarelo das persianas, ou melhor, "uma faixa de amarelo pálido"2 (WOOLF, 2015, p. 4), como diz Susan ao ver o nascer do sol, e do ritmado quebrar das ondas, ou ainda, "o murmúrio das ondas no ar"3 (WOOLF, 2015, p. 9), como alerta Bernard, que se faz essencial a escuta atenta das questões originárias trazidas pelas imagens do romance. O sentido de tais imagens perdura no bater do coração apaixonado ao reconhecer o grande momento basilar porque presente em todos os outros instantes de vida, porque parte do todo de uma vida que se faz obra, deixando operar mundo, manifestado na unidade representativa da duração do tempo pela memória.

As imagens deixam entrever alguma coisa. Elas dizem o nomeável, marcando, pela memória, o sentimento ocasionado pelo evento representado. A marca dessas imagens passa a integrar o conjunto de momentos disponíveis à rememoração das partes de um todo que compõem uma vida, por terem sido incorporadas e, assim, representarem o todo que um indivíduo é. Por outro lado, o inominável é sugerido no vigor de realização representativa do que a língua não consegue acessar, silenciando e, paradoxalmente, potencializando as possibilidades ofertadas pela linguagem. Estranhamos a familiaridade de algo que ainda não conhecemos, mas cujo eco ressoa nos labirintos do espírito por acordar o que estava adormecido, e cuja existência sequer podíamos imaginar. Imaginamos o inominável a partir de nomes, e, assim, fabricamos a textura de uma realidade visualizável e passível somente de reconhecimento intuitivo.

Se, na esteira de Deleuze e Guatarri (2012), pensarmos que uma grande Onda abstrata, parece percorrer todo o plano da narrativa e coadunar todas as personagens em um mesmo e único movimento, a imagem das ondas parece dar o tom e o peso que sua repetição, a partir da diferença, enseja uma forma que aos poucos pode ser avistada. A composição de imagens que reiteradamente aparecem no texto woolfiano serve de unidade mínima para pensarmos a forma de sua prosa modernista. De suma importância são as imagens da água, por exemplo, que ajudam a compor cenas que representativamente vem à superfície e marcam a narrativa em momentos altamente poéticos, além de caracteristicamente alicerçarem os mundos criados em seus livros e darem a textura de vida encarnada em suas personagens. As imagens poéticas, em seu ir e vir no romance The Waves, mais especificamente, sustentam as possíveis conexões e interpretações a serem feitas de maneira muito particular, porque se querem fluidas, resguardando o potencial de novas e inesperadas maneiras de se firmar nos fluxos que nos impelem e por vezes nos arrastam no movimento circular de reconhecimento das insinuações da morte enquanto vivemos.

A qualidade de uma forma maleável, podendo se dar de inúmeras maneiras, toma uma significância porque repetidamente pode ser avistada em obras de arte das mais diversas. Em seu livro Art (1914), Clive Bell, cunhado de Virginia Woolf e também integrante do grupo de

\footnotetext{
a slab of pale yellow

the murmur of the waves in the air
} 
Bloomsbury, elabora o conceito de significant form, que veio a traduzir a filosofia por trás do método empregado pelos pintores pós-impressionistas, cujas obras ele e Roger Fry haviam reunido para a exposição de 1910 intitulada Manet and the Post-Impressionists. Em seu ensaio intitulado "The Artistic Problem" (1919), Bell retoma as questões da significant form e da emoção estética novamente. Nas mais diversas obras de arte, ele afirma que as linhas e as cores são combinadas de tal modo que certas formas e relações de formas estimulam nossas emoções estéticas. Essas relações e combinações de linhas e cores, essas formas que proporcionam emoções estéticas são o que ele chama de significant form, isto é, uma qualidade comum a todas as obras de artes plásticas, sem a qual uma obra de arte não pode operar (BELL, 1993).

Ainda que Bell ancore seu conceito nos seus estudos das artes plásticas, suas ideias tiveram influência dentro do grupo de Bloomsbury, passando das formas das artes plásticas para também as das obras literárias, fundamentando imagens persistentes cuja significância opera e conecta todas as partes ao todo da obra. O que está sendo questionado em grande parte no ensaio de Bell é a representação artística. O crítico discorre sobre a criação da obra, levando em consideração momentos que considera cruciais para a composição da forma. Primeiramente, o artista é tomado por um estado agudo e de agitação solidária, suscitado por uma árvore, um ônibus, o grito de apitos, o canto dos pássaros, o cheiro de porco assado, um gesto, um olhar, qualquer evento trivial que provoque a crise, inflando nele um desejo de expressar-se, ou melhor, de criar uma forma que faça justiça ao sentimento, que comemore o momento de êxtase (BELL, 1993). O problema artístico reside no empenho de criação da combinação de uma forma cuja significância seja depreendida por expressar a experiência emotiva pela qual o artista é sensibilizado (BELL, 1993). Ele acrescenta que, com a crise da representação, o romance "proporciona para a maioria dos escritores um problema insatisfatório, porque insuficientemente rigoroso"4 (BELL, 1993, p. 105). O entrave está em dar forma à experiência de modo a criticar uma mera preocupação com uma representação fidedigna das práticas e das instituições sociais. No caso da literatura, isso significa dar forma às novas e possíveis combinações que a língua oferece, ou ainda, nas palavras de Woolf em "Craftsmanship" (1937), o romancista deve se perguntar: "Como poderíamos combinar as palavras velhas em novas ordenações para que elas sobrevivam, para que criem beleza, para que digam a verdade" (WOOLF, 2009, p. 89)?

Também integrante do grupo de Bloomsbury, Desmond MacCarthy escreveu o ensaio intitulado "The Post-Impressionists" (1910), em que traça as fronteiras de diálogo entre os pintores impressionistas e os pós-impressionistas. MacCarthy (1993) aponta que aquilo que tanto os impressionistas como os pós-impressionistas têm em comum é a resolução de cada artista a expressar seu próprio temperamento e nunca permitir que ideias contemporâneas ditem o que é belo, significativo e o que vale a pena ser pintado. Os pós-impressionistas, no entanto, conseguem ir além do estudo de luz e cores, investigando as emoções que os objetos evocam por si mesmos, enquanto que os impressionistas, desse modo, ainda estão presos à representação,

\footnotetext{
${ }^{4}$ (...) affords for most writers an unsatisfactory, because insufficiently rigorous, problem.

${ }^{5}$ How can we combine the old words in new orders so that they survive, so that they create beauty, so that they tell the truth?
} 
pois a cintilação da profusão de luz e cores em suas telas ainda tem por fundamento a mimeses, que, fundamentalmente, busca representar os elementos da natureza, ainda que isso implique a constatação de que algumas características sejam mais enfatizadas que outras. Uma árvore representada a partir de luz, brilho e cor ainda é uma tentativa de objetivamente representar a árvore em si mesma e não de apresentar as relações humanas com a árvore. Assim sendo, o Pós-impressionismo se caracteriza por ser uma escola que permite mais criatividade e auto expressão do artista, o que possibilita uma melhor compreensão da crítica aos impressionistas, considerados por demais naturalistas.

Ao tentar ilustrar seu ponto, MacCarthy (1993) interpreta o processo criativo de Van Gogh como uma aceitação geral da aparência da natureza. Entretanto, anterior a toda cena e a todo objeto está, primeiramente, a procura pela qualidade que originalmente aguçou sua curiosidade. E é exatamente isso que ele está determinado a traduzir a qualquer custo. Essa expressividade original, em oposição à representação, é apresentada pela síntese do design, o artista estando preparado para conscientemente subordinar seu poder de representação o mais plausivelmente possível. Suas telas entreabrem os recessos do belo por convidarem ao pensamento na medida em que insinuam aquilo que atrai e encanta o olhar, que percebe mas não consegue traduzir em palavras o que registra e assimila. Assim, surge a propriedade de um novo modo de compreensão da realidade, não mais representada mas sim apresentada porque, imaginada e criada, opera possibilidades de mundos onde habitar.

A influência dos artistas pós-impressionistas pode ser depreendida em The Waves pela maneira como o movimento da narrativa apresenta a linguagem como síntese dos movimentos, fluxos e repousos dos ciclos da vida através de imagens e cenas. Essas imagens e cenas parecem evocar um tom e um ritmo, deixando a impressão de vidas que poeticamente são levadas e se deixam levar pelos espaços e lacunas em que o próprio movimento da vida só pode ser brecado pelos baques, cortes e feridas da morte, intermitentemente esperados e cumpridos. Em seus diários, Woolf comenta sobre o processo de escrita do romance, que originariamente tinha em mente chamar de The Moths: "Bem, tudo isso é obviamente a vida 'real'; e o nada vem somente na ausência disso. Com certeza já provei isso na última meia hora. Tudo se torna verde e vivo em mim quando começo a pensar sobre The Moths. Também penso que estamos mais bem preparados para adentrar o outro -"6 (WOOLF, 1982, p. 141). Adentrar ao outro requer viver nos interstícios entre realidade e ficção, verdade e falsidade, vida e morte de tal modo que essas instâncias se misturem a ponto de não mais poderem ser dissociadas porque entranhadas na outridade de onde nascem e para onde voltam - identidade desembocando em alteridade passa a ser a máxima da obra em questão.

Assim sendo, o artifício da forma, que tanto preocupa a artífice, está em atribuir a cada personagem a densidade que cada identidade comporta quando logo em seguida tem suas crenças, opiniões, sentimentos e sensações reavaliados sob novas perspectivas à maneira de recorte e

\footnotetext{
${ }^{6}$ Well all this is of course the "real" life; and nothingness only comes in the absence of this. I have proved this quite certainly in the past half hour. Everything becomes green and vivified in me when I begin to think of The Moths. Also, I think, one is much better able to enter into others -
} 
colagem de cores e brilhos, luzes e sombras que encerrem a multiplicidade una que o todo de um mosaico compõe: "Como terminar, senão com uma discussão tremenda em que cada vida tenha uma voz - um mosaico - não sei ao certo"7 (WOOLF, 1982, p. 153). Woolf aos poucos, em seus diários, parece desenhar a forma do romance combinando e recombinando momentos e impressões múltiplas de experiências de si e dos outros, lendo e relendo autores canônicos da literatura inglesa, escrevendo ensaios curtos e resenhas, ouvindo Beethoven, fazendo o próprio movimento da obra se insinuar como uma ideia recorrente. Essa ideia é arduamente trabalhada e canetada nas fases de revisão dos manuscritos para, enfim, operar um mundo cuja integralidade e senso de realidade supera a mera tentativa de capturar o cotidiano de personagens manipuladas com a intenção de recriar a realidade em menor escala que depreciaria o complexo processo de imaginação, criação e leitura do romance. Ela escreve ainda em seu diário que

o que me interessa no último estágio era a liberdade e a audácia com que minha imaginação pegou, usou e descartou todas as imagens, todos os símbolos que eu havia preparado. Estou certa de que esta é a maneira correta de usá-los - não em conjuntos, como eu tinha tentado primeiramente, coerentemente, mas simplesmente como imagens, nunca completamente desvendadas, somente sugeridas. Portanto, espero ter preservado o som do mar e dos pássaros, do amanhecer e do jardim inconscientemente presentes, trabalhando sob a superfície ${ }^{8}$ (WOOLF, 1982, p. 165).

Essa preocupação com a forma já vinha sendo desenvolvida em vários de seus escritos e, em seu ensaio "Mr. Bennett and Mrs. Brown" (1919;1924), mais claramente podemos apreciar as considerações que Woolf vinha fazendo acerca da tradição à maneira como seus contemporâneos nela poderiam interferir. Publicado posteriormente na revista The Criterion, de T. S. Eliot em julho de 1924 sob o título "Character in Fiction", o ensaio "Mr. Bennett and Mrs. Brown" foi aprimorado a partir de uma palestra dada para a Cambridge Heretics Society como uma resposta ao canônico ensaio de T. S. Eliot “Tradition and the Individual Talent” (1919).

Em "Mr. Bennett and Mrs. Brown" (1919) são traçadas algumas das distinções mais marcantes da descrição de personagens na ficção dos escritores vitorianos, eduardianos e georgianos. Para os vitorianos, os detalhes com que as personagens eram descritas deveriam ser de tal modo minuciosos que o conjunto desse vida a todos os tipos sociais em suas idiossincrasias, mostrando que eram capazes de amar, zombar, caçar, casar, seja nas cortes, nos chalés ou em barracos. Tal maestria alcançada, no entanto, parecia ter desmotivado os eduardianos a também perseguir o detalhismo da geração anterior, que talvez a eles parecesse forçado, e, assim, eles se imbuem da tarefa de reformismo por entenderem que os valores cristãos estavam sob ameaça na sociedade corrupta da virada do século. Os escritores georgianos, nesse cenário, deviam empenhar-se da busca por uma forma que melhor conservasse as peculiaridades do hábito e as colocasse em

\footnotetext{
7 How to end, save by a tremendous discussion, in which every life shall have its voice - a mosaic - I do not know 8 What interests me in the last stage was the freedom and boldness with which my imagination picked up, used and tossed aside all the images, symbols which I had prepared. I am sure that this is the right way of using them - not in set pieces, as I had tried at first, coherently, but simply as images, never making them work out; only suggest. Thus I hope to have kept the sound of the sea and the birds, dawn and garden subconsciously present, doing their work under ground
} 
conversa com a grandiosidade das ideias, dando oportunidade para que as relações pudessem suscitar os conflitos humanos pelos quais suas personagens deviam passar.

Este ensaio tem muitas de suas questões retomadas sob o título de "Character in Fiction" (1924). Ali pode ser encontrada a famosa assertiva de Woolf, segundo a qual "em ou perto de dezembro de 1910 o caráter humano mudou"9 (WOOLF, 2015, p. 38). Isso significa que "todas as relações humanas haviam mudado - aquelas entre patrões e empregados, maridos e mulheres, pais e filhos. E quando as relações humanas mudam simultaneamente há uma mudança na religião, na conduta, na política e na literatura" ${ }^{10}$ (WOOLF, 2015, p. 38). A grande mudança anunciada, e apresentada nas telas dos pintores pós-impressionistas na exposição Manet and the Post-Impressionists, passa a ser enunciada quando entendida a crise da representação e os problemas daí advindos, pois o que a ficção georgiana questionava eram as condições de possibilidade para representar para além das relações interpessoais, e suas repercussões intrapessoais, e morais com a falência dos grandes sistemas religiosos, rearticulando complicações existenciais que possibilitassem uma nova maneira de compreender o caráter humano.

Virginia Woolf mais uma vez busca, com a personagem Mrs. Brown, articular uma estética feminista cujos objetivos de ganhos materiais revelam as mudanças que já vinham ocorrendo e as outras tantas por que insistentemente batalhava em seus escritos. Assim, ela descreve a nova maneira com que a cozinheira é representada na literatura vitoriana e como a transição é efetivada para a georgiana de modo que a personagem seja agora apresentada aos leitores dentro do mundo arquitetado pelo escritor modernista:

Na vida, pode-se ver a mudança, se eu puder usar uma ilustração doméstica, na personagem da cozinheira. A cozinheira vitoriana vivia como um leviatã nas profundezas, formidável, silenciosa, obscura, inescrutável; a cozinheira georgiana é uma criatura de raios solares e ar fresco; entrando e saindo da sala de estar, agora pegando o Daily Herald emprestado, agora pedindo conselhos sobre um chapéu ${ }^{11}$ (WOOLF, 2015, p. 38).

Comparada ao leviatã bíblico, a cozinheira vitoriana permanece inacessível nos confins da casa, estando tão remota quanto a imaginação pode criar monstros horríveis porque impenetráveis e, assim, engrandecidos pelos temores psicológicos de uma sociedade cujas neuroses foram tão bem analisadas ao final do século XIX e início do XX por Sigmund Freud. A cozinheira georgiana, por outro lado, pode sair dos recessos da casa para circular por entre transeuntes no mundo dos vivos e, não só respirar um ar mais puro, mas também se informar sobre os acontecimentos destacados no Daily Herald, pois a leitura que pratica se expande agora para além dos romances dramatizados nos folhetins. Por fim, a cozinheira se torna um emblema da estética

\footnotetext{
9 (...) on or about December 1910 human character changed.

10 All human relations have shifted - those between masters and servants, husbands and wives, parents and children. And when human relations change there is at the same time a change in religion, conduct, politics and literature.

11 In life one can see the change, if I may use a homely illustration, in the character of one's cook. The Victorian cook lived like a leviathan in the lower depths, formidable, silent, obscure, inscrutable; the Georgian cook is a creature of sunshine and fresh air; in and out of the drawing room, now to borrow the Daily Herald, now to ask advice about a hat.
} 
woolfiana, figurando ao lado de diversas outras personagens femininas, por sintetizar questões materiais e poéticas simultaneamente, revelando a nova ordem que a sociedade da época já reclamava e também demandando a atenção à apresentação do caráter complexo de todo e qualquer personagem que escritores pudessem vir a criar.

A grande questão da forma a ser criada é discutida no ensaio "Poetry, Fiction and the Future" (1927), em que Virginia Woolf prevê uma nova escrita, uma "prosa que tem muitas das características da poesia. Ela terá um pouco da exaltação da poesia, mas muito da trivialidade da prosa. Será dramática, mas não será exatamente uma peça. Será lida, mas não atuada"12 (WOOLF, 2009, p. 81) - uma prosa lírica necessária aos tempos modernos. Suas cenas deverão convergir no palco onde personagens agem e refletem sobre sua posição no mundo sem, no entanto, excessivamente registrar detalhes, mas somente dando indícios de uma silhueta que possibilite, ao leitor, compreender a relação de uma mente para com a história das ideias, grandes e pequenas, como Woolf elenca ao final do ensaio: "rosas e rouxinóis, o alvorecer, o pôr-do-sol, a vida, a morte e o destino"13 (WOOLF, 2009, p. 80). O romance se guiará pelos caminhos do dizer poético, aprofundando-se nos questionamentos existenciais das personagens, não se limitando, assim, ao escopo das relações interpessoais. Sua descida em movimento vertical, e não mais somente horizontal indicará um ponto de convergência entre indivíduos que cultivam a experiência de solidão a ser compartilhada e experienciada pela escrita e pela leitura de ficção. As imagens poéticas poderão traduzir a linguagem que reúne leitores comuns, pensando e sendo em comunidade.

Seu projeto modernista está ancorado em sua política que introduz a figura feminina como antídoto para equilibrar as forças masculinas, que até então organizavam a sociedade patriarcal, promovendo uma sentença ${ }^{14}$ outra, feminina, de modo a atingir a linguagem que chama de andrógina. Tal projeto também se fundamenta no ser quando, por momentos apenas, podemos fazer sentido das questões que fundam nossa história nos moments of being ${ }^{15}$. O romance The Waves perfeitamente ilustra esse projeto ao problematizar a questão da construção de uma identidade própria frente à alteridade coletiva, cuja radicalidade é atingida ao ultrapassar os limites da propriedade e desembocar na despersonalização de suas personagens. Assim, Jane Goldman bem aponta, em seu ensaio "From Mrs. Dalloway to The Waves" que "o design dessas formas alternantes e antifônicas permite que The Waves explore a política da subjetividade poética (individual e coletiva) e os processos de autoconstrução assim como a possiblidade da ausência de uma identidade"16 (GOLDMAN, 2012, p. 65). Os interlúdios introduzem a possibilidade de despersonalização e integração com os elementos naturais e são intercalados, na estrutura total

\footnotetext{
12 (...) prose which has many of the characteristics of poetry. It will have something of the exaltation of poetry, but much of the ordinariness of prose. It will be dramatic, and yet not a play. It will be read, not acted.

${ }^{13}$ (...) roses and nightingales, the dawn, the sunset, life, death, and fate.

${ }_{14}$ Cf. A Room of One's Own (1929) para um melhor entendimento da distinção que Virginia Woolf estabelece entre a sentença feminina e a sentença masculina.

${ }^{15}$ Cf. Moments of Being para um melhor entendimento da distinção que Virginia Woolf estabelece entre moment of being e moment of non-being.

16 The design of these alternating, antiphonal forms allows The Waves to explore the politics of poetic subjectivity (individual and collective) and the processes of self-fashioning, as well as the possibility of the absence of the self.
} 
do romance, com as vozes das personagens, que, alternadamente, têm suas falas mescladas umas nas outras, confundindo a construção do sujeito individual do coletivo na ficção.

Isso complexifica o trabalho da crítica, na medida em que o significado obtuso traduzido pelas imagens complica a metalinguagem. Como dar conta daquilo que se diz pela potencialidade encerrada no silêncio das palavras a partir de termos técnicos que identifiquem e mensurem um efeito que de antemão já se quer produzido e que seja passível de reprodução? Qual seria a linguagem apropriada para nomear uma técnica narrativa que traduza o inominável e a inconsolável apatia que a natureza tem para com o ser humano? Os interlúdios por si só esboçam cenas da grandiosidade da natureza. Neles, o uso de figuras de linguagem, como a personificação, ajuda a corroborar o abismo que jaz entre o humano e o não-humano, ambos interagindo na reciprocidade das leis de ação e reação, mas também distanciando-se um do outro por conta da insuperável e monumental indiferença dos elementos frente ao sentimento e ao pensamento humanos. No capítulo sobre The Waves em seu livro The Novels of Virginia Woolf(1977), Hermione Lee já apontava que "o efeito do antropomorfismo é peculiar; as cenas inumanas parecem, por conta dele, irromper com vida ativa e a ameaçar (como a atividade da natureza na seção 'Time Passes' de To the Lighthouse) a consciência humana individual"17 (LEE, 2010, p. 167).

Assim, podem ser coletados alguns exemplos do primeiro interlúdio, como: "O mar estava levemente encrespado como um pano enrugado"18 (WOOLF, 2015, p. 3) e "a onda pausou e depois subiu mais uma vez, suspirando como uma pessoa adormecida cuja respiração vai e vem inconscientemente"19 (WOOLF, 2015, p. 3) que contrastam pela força que retém em oposição ao espaço humano da casa, que é descrito como "fraco e insubstancial"20 (WOOLF, 2015, p. 3). O contraste claro entre o reino natural e o mundo humano poderia à primeira vista ser atenuado com o uso da personificação dos elementos não-humanos, mas o que se insinua nesta primeira cena é a grandiosidade das forças indomáveis, em última instância, do mar, mantendo a presença humana às sombras do que ainda sequer tem substância que fundamente. O ritmo depreendido da musicalidade entoada pelas ondas ajuda a corroborar uma dinâmica muito maior que todos nós e da qual apenas fazemos parte sem chances reais de controle e domínio.

Julia Briggs, em seu artigo “The Novels of the 1930s”, retoma passagens dos diários de Woolf nos quais a escritora refletia sobre a natureza do narrador dos interlúdios, cuja voz deveria entoar uma fala despersonalizada, ou melhor, "eyeless" que, ainda seguindo a tradição romântica, poderia ser compreendida como "I-less", algo que já havia sido ensaiado no romance To the Lighthouse (1927) na seção “Time Passes” (BRIGGS, 2012, p. 73). Empreendendo essa despersonalização, que se estende mais claramente nos interlúdios, mas também invade as principais seções do romance, Woolf consegue pôr em prática sua crítica ao realismo eduardiano, na medida em que pensa o método que desenvolve a forma de The Waves, misturando uma personagem à

\footnotetext{
17 the effect of anthropomorphism is peculiar; the inhuman scenes seem, because of it, to be bursting with active life, and to provide (like the activity of nature in the 'Time Passes' section of To the Lighthouse) a threat to the individual human consciousness.

18 the sea was slightly creased as if a cloth had wrinkles in it

19 the wave paused, and then drew out again, sighing like a sleeper whose breath comes and goes unconsciously

$20 \mathrm{dim}$ and unsubstantial
} 
outra, o elemento não-humano ao humano, a claridade à escuridão, conseguindo abrir interstícios de silêncio na trama de modo a, pelo método que parecia intuir em "Modern Fiction" (1919), envolver, pela trama, a luz que suas personagens irradiam sem totalmente poder capturá-la tão fugidia é sua natureza.

Vale ressaltar novamente que o romance The Waves inicialmente teve como título provisório The Moths, o que é muito sugestivo no universo woolfiano na tentativa de compreender as fronteiras entre o humano e o não humano, a vida e a morte. Em seu ensaio "The Death of the Moth” (1942), Virginia Woolf descreve as forças de vida e as forças de morte que disputam na clareira de uma manhã agradável do mês de setembro, numa manhã tão intensa em atividade que acreditaríamos testemunhar um dia de alto verão. Essa eletricidade povoa o dia e os diferentes elementos que o habitam, o navio à distância, o trabalho da enxada nas mãos humanas, os pássaros nas árvores, e até mesmo uma mariposa em seu voo. Ínfimo espécime pulsando vida, a mariposa parece ser digna de pena por não poder participar, em maior escala, dos ritmos que vibram nesta manhã. "Tão frequentemente quanto ela cruzava o vidro da janela, eu imaginava que um fio de luz vital se tornava visível. Ela era pouca ou quase nenhuma vida"21 (WOOLF, 1970, p. 4). Repentinamente, entretanto, algo parece falhar, a energia contagiante que agitava seu bater desesperado de asas parece sucumbir frente a uma indisposição, ocasionada pela inércia iminente. Paralisia e quietude tomam conta de maneira impessoal e generalizada. A morte irrompe dos interstícios do que antes era vida. Insólita é a passagem de vida para segundos depois transformar-se em mero corpo ressequido. Acometidos pelo espanto, não podemos evitar o estranhamento de um momento impregnado de familiaridade, mas, ainda assim, inaugural no desconforto com que percebemos a ubiquidade da morte: "Assim como a vida alguns minutos atrás, a morte agora era tão estranha quanto"22 (WOOLF, 1970, p. 6).

O romance The Waves trabalha esses entre-lugares ao gestualizar o silêncio que permeia as imagens e o ritmo cíclico e constante que sonoriza uma qualidade mística ritualizada em prosa. Imagens do não-humano podem ser divisadas na literatura woolfiana na medida em que o distanciamento de uma voz narradora não-humana apresenta a seus leitores o mundo onde o homem deixa sua marca e intervém, abrindo uma clareira frente ao domínio do natural, de onde vem, mas do qual se destaca, pensando. O não-humano abre os interstícios de intuir, mas não poder verbalizar, pressentir, sem ter as ferramentas que veiculem e consolidem o indizível, o silêncio, o nada em que, pela linguagem, o ser humano intervém. Esse silêncio que não pode ser pronunciado sugere o mistério que move o fazer literário em novas obras cuja expressão anuncia o abismo último: viver sem garantias e genuinamente imbuir-se da tarefa do pensamento.

\footnotetext{
${ }^{21}$ As often as he crossed the pane, I could fancy that a thread of vital light became visible. He was little or nothing but life.

22 Just as life had been a few minutes before, so death was now as strange.
} 


\section{REFERÊNCIAS}

BELL, Clive. The Artistic Problem. In: ROSENBAUM, S. P. A Bloomsbury Group Reader. Oxford: Blackwell Publishers, 1993, p. 102-106.

BRIGGS, Julia. The Novels of the 1930s. In: SELLERS, Susan (ed.). The Cambridge Companion to Virginia Woolf. Cambridge: Cambridge University Press, 2012, p. 70-88.

DELEUZE, Gilles \& GUATTARI, Félix. Mil platôs - Capitalismo e esquizofrenia 2. Volume 4. São Paulo: Editora 34, 2012.

GOLDMAN, Jane. From Mrs. Dalloway to The Waves. In: SELLERS, Susan (ed.). The Cambridge Companion to Virginia Woolf. Cambridge: Cambridge University Press, 2012, p. 49-69.

LEE, Hermione. The Waves 1931. In: The Novels of Virginia Woolf. New York: Routledge, 2010, p. 158-179. MACCARTHY, Desmond. The Post-Impressionists. In: ROSENBAUM, S. P. A Bloomsbury Group Reader. Oxford: Blackwell Publishers, 1993, p. 97-101.

WOOLF, Virginia. A Writer's Diary. New York: Harcourt, 1982.

WOOLF, Virginia. Character in Fiction. In: Selected Essays. London: Oxford University Press, 2009, p. 37-54. WOOLF, Virginia. Craftsmanship. In: Selected Essays. London: Oxford University Press, 2009, p. 85-91. WOOLF, Virginia. Modern Fiction. In: Selected Essays. London: Oxford University Press, 2009, p. 6-12. WOOLF, Virginia. A Sketch of the Past. In: Moments of Being. New York: Harcourt Inc, 1985, p. 64-159. WOOLF, Virginia. Mr. Bennett and Mrs. Brown. In: Selected Essays. London: Oxford University Press, 2009, p. 32-36.

WOOLF, Virginia. Poetry, Fiction and the Future. In: Selected Essays. London: Oxford University Press, 2009, p. 74-84.

WOOLF, Virginia. The Death of the Moth. In: The Death of the Moth and Other Essays. London: Harcourt Brace, 1970, p. 3-6.

WOOLF, Virginia. The Waves. London: Oxford University Press, 2015. 